\title{
Somogy megye csípőszúnyogjainak katalógusa (Diptera: Culicidae)
}

\author{
TÓTH SÁNDOR
}

Tótr S.: Checklist of mosquito of Somogy county (Diptera: Culicidae)

Abstract: The mosquito fauna of Somogy county is well known. This is especially true for certain areas of the county, namely the region around Lake Balaton, alongside the River Dráva and Boronka-melléki Landscape Protection Area. According to the available data, the occurrence of $80 \%$ of the Hungarian fauna (35 species +1 subspecies) can be proved to exist in the area of Somogy county. The fauna is rich in rare and special elements, such as: Aedes communis (De Geer, 1776), Aedes leucomelas (Meigen, 1804), Aedes pulchritarsis (Rondani, 1872), Anopheles algeriensis Theobald, 1903, Anopheles hyrcanus (Pallas, 1771), Culex theileri Theobald, 1903, Culiseta alaskaensis (Ludlow, 1906), Culiseta subochrea (Edwards, 1921).

\section{Bevezetés}

Magyarország csípószúnyog faunája általánosságban jól kutatottnak nevezhető. Ebben közrejátszott az, hogy három fajuk egyes vidékeinken, az egykor népbetegségnek számító malária terjesztőjeként vált ismerté. Nem véletlen, hogy a maláriaszúnyogok hazai elterjedésének és a betegség átvitelében játszott szerepének tisztázását végző munkacsoport egyik kutatóbázisa, éppen a Somogy megyei Iharosberényben, a maláriával erôsen fertőzött vidékünkön múködött az 1930-as évek közepén. A munkát irányító szúnyogkutatók, Lörincz Ferenc és Mihályi Ferenc, több közleményben (LóRINCZ-MiHÁLYI 1937a, 1937b, 1938) számoltak be két maláriaszúnyog faj (Anopheles maculipennis Meigen, 1818, Anopheles messeae Falleroni, 1926) vizsgálatával kapcsolatos eredményeikról.

Szerencsére a maláriás megbetegedések az elmúlt évtizedekben már csak elvétve fordultak elö. A szúnyogkutatás az 1930-as évek végétól elsósorban a fauna teljes megismerésére, az egyes fajok a szúnyogártalomban betöltött szerepének tisztázására, valamint a szúnyogok elleni védekezés lehetőségeinek kidolgozására irányult. Ez a tevékenység már korábban is kiemelt szerepet kapott a Balaton térségében. A munka intenzitása fokozódott, amikor a Magyar Tudományos Akadémia a szúnyogprobléma országos tisztázása érdekében, 1950-ben munkabizottságot hozott létre. Ennek keretében, 1950-1951-ben, Mihályi Ferenc és Soós Árpád részletes vizsgálatokat végeztek a Balaton parti sávjában, beleértve természetesen a tó Somogy megyéhez tartozó részét is (SOÓS-MIHÁLYI 1952).

A balatoni szúnyogprobléma az 1970-es évek elsó felében került ismét napirendre. A jelenleg is folyó vizsgálatok eredményeképpen a terület a csípószúnyogok szempontjából ma már jól kutatott. Ugyanez azonban nem mondható el Somogy megyéról általában, mivel a tó partvidékén kívül érdemleges vizsgálatok csak a Dráva-mentén (TóTH 1995), a Boronka-melléki Tájvédelmi 
Körzetben (TóTH 1992), valamint a Kis-Balaton területén (TóTH 1996) történtek.

Érdemes megemlíteni, hogy Somogy megyére vonatkozó csípôszúnyog adatokat már mintegy száz évvel ezelótt is közöltek. A Magyar Birodalom Állatvilága (Fauna Regni Hungariae) kétszárnyúakkal foglalkozó fejezetében (Thalhammer 1899) két faj [Aedes annulipes (Meigen, 1830), Aedes cantans (Meigen, 1818)] adatát találhatjuk Csurgóról. Néhány évvel késóbb jelent meg a magyarországi szúnyogfélék rendszertani ismertetésével foglalkozó munka (KERTÉSZ 1904), melyben a szerző három faj [Aedes dorsalis (Meigen, 1830), Culex pipiens Linnaeus, 1758, Mansonia richiardii (Ficalbi, 1889)] adatát említi a Balaton déli partjáról, Ószödról (Balatonőszöd).

A megye csípószúnyog-faunája összességében jól kutatottnak nevezhetô, mivel a hazai taxonok kereken $80 \%$-áról (35 faj +1 alfaj) rendelkezünk már innen előfordulási adatokkal.

\section{A Somogyból ismert fajok jegyzéke}

Aedes annulipes (Meigen, 1830) - Mihályi 1941, Mihályi et al. 1952a, 1953, Thalhammer 1899, Tóth 1981, 1992, 1995, 1996

Aedes cantans (Meigen, 1818) - Mihályi 1941, Mihályi et al. 1952a, 1953, Thalhammer 1899, Tóth 1981, 1992, 1995, 1996

Aedes caspius (Pallas, 1771) - Mihályi 1941, Mihályi et al. 1952a, 1953, Tóth 1981, 1996

Aedes cataphylla Dyar, 1916 - Mihályi 1941, Mihályi et al. 1952a, 1953, Tóth 1992, 1996

Aedes cinereus Meigen, 1818 - Mihályi 1941, Mihályi et al. 1952a, 1953, Tóth 1981, 1992, 1995, 1996

Aedes communis (De Geer, 1776) - Mihályi et al. 1952a, Mihályi - Gulyás 1963, 'Tóth (elókészületben). Meglehetôsen ritka, Magyarország kevés helyáröl ismeert faj.

Aedes dorsalis (Meigen, 1830) - Kertész 1904, Mihályi 1941, Mihályi et al. 1952a, 1953, Tóth (elókészületben)

Aedes excrucians (Walker, 1856) - Mihályi et al. 1952a, Mihályi et al. 1953, Tóth 1981, 1992, 1995, 1996

Aedes flavescens (Müller, 1764) - Mihályi 1941, Mihályi et al. 1952a, 1953, Szilády 1941, Tóth 1981, 1992, 1995, 1996

Aedes geniculatus Olivier, 1791) - Mihályi 1941, Mihályi et al. 1952a, 1953, Tóth 1981, 1995: Lárvája faodvak vizében (dendrotelma) fejlödik.

Aedes leucomelas (Meigen, 1804) - Mihályi et al. 1952a, 1953, Tóth (elókészületben). Ritka.

Aedes pulchritarsis (Rondani, 1872) - Tóth (elókészületben). Magyarország csupán néhány pontjáról kimutatott ritka faj.

Aedes rossicus Dolbeshkin, Goritzkaja \& Mitrofanova, 1930 - Tóth 1981, 1995

Aedes rusticus (Rossi, 1790) - Mihályi 1941, Mihályi et al. 1952a, 1953

Aedes sticticus (Meigen, 1838) - Mihályi et al. 1952a, Mihályi et al. 1953, Tóth 1981, 1992, 1995, 1996

Aedes vexans (Meigen, 1830) - Mihályi 1941, Mihályi et al. 1952a, 1953, Szilády 1941, Tóth 1981, 1992, 1995, 1996

Anopheles algeriensis Theobald, 1903 - Tóth (elökészületben)

Anopheles atroparvus Van Thiel, 1927 - Tóth (elókészületben). Elsősorban az Alföld szikes vidékeire jellemző faj.

Anopheles claviger (Meigen, 1804) - Mihályi 1941, Mihályi et al. 1952a, 1953, Tóth 1981, 1992, 1996

Anopheles hyrcanus (Pallas, 1771) - Mihályi Gulyás 1963, Mihályi et al. 1952a, 1953, Tóth 1992, 1996

Anopheles maculipennis Meigen, 1818 . Lónincz-Mihályi 1937a, 1937b, 1938, Mihályi 1941, Mihályi et al. 1952a, 1953, Tóth 1981, 1992, 1995, 1996

Anopheles messeae Falleroni, 1926 . Lórincz-Mihályi 1937a, 1937b, 1938, Tóth 1996

Anopheles plumbeus Stephens, 1828 - Mihályi 1941, Mihályi et al. 1952a, Tóth 1981, 1996. Faodvak vizében (dendrotelma) fejlódó faj.

Culex hortensis Ficalbi, 1890 - Mihályi et al. 1952a, 1953, Tóth 1996. Ritka, Magyarország- 


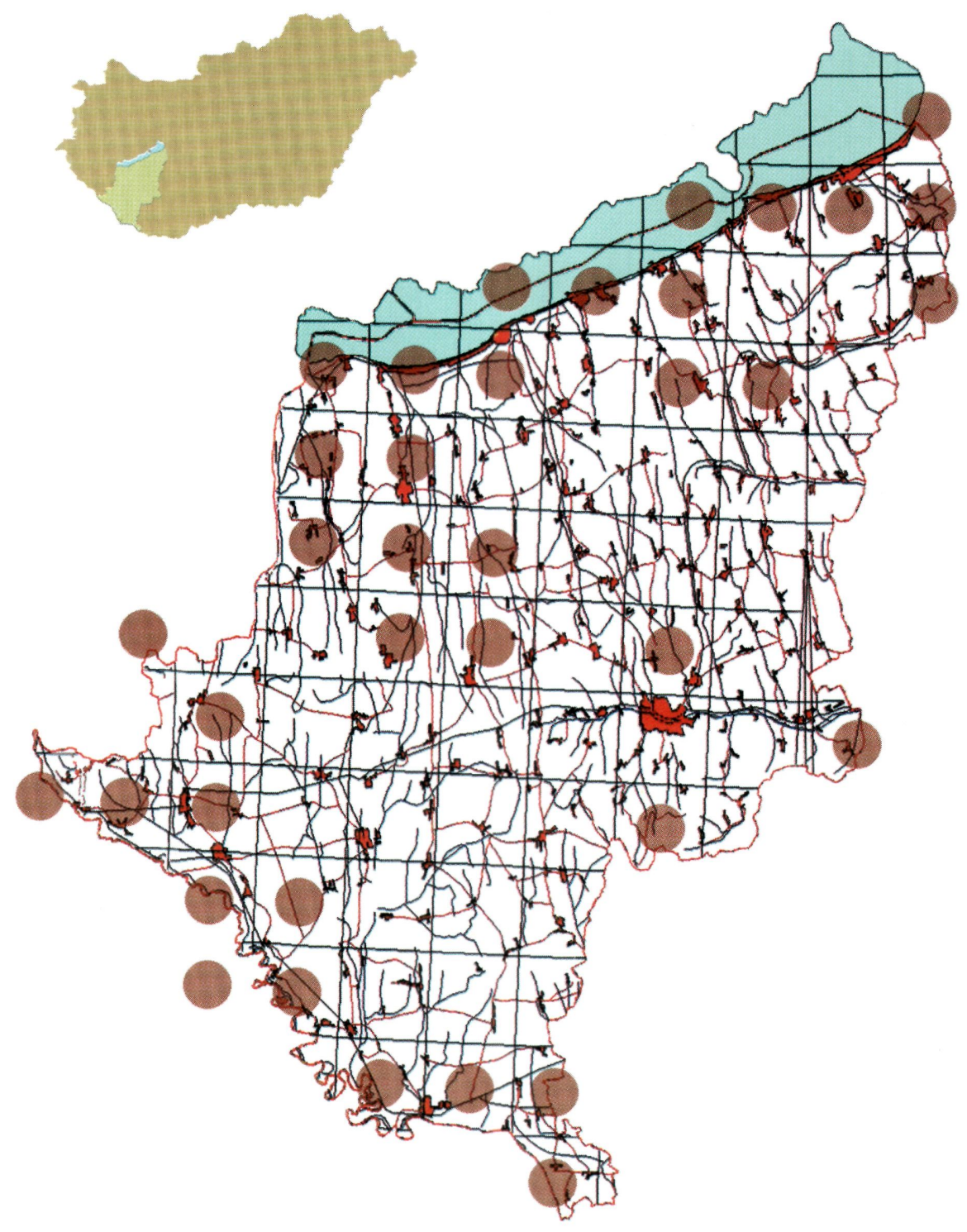

l. ábra: Culicidae 10x10 km-es UTM mintavételi helyek Somogy megyében 


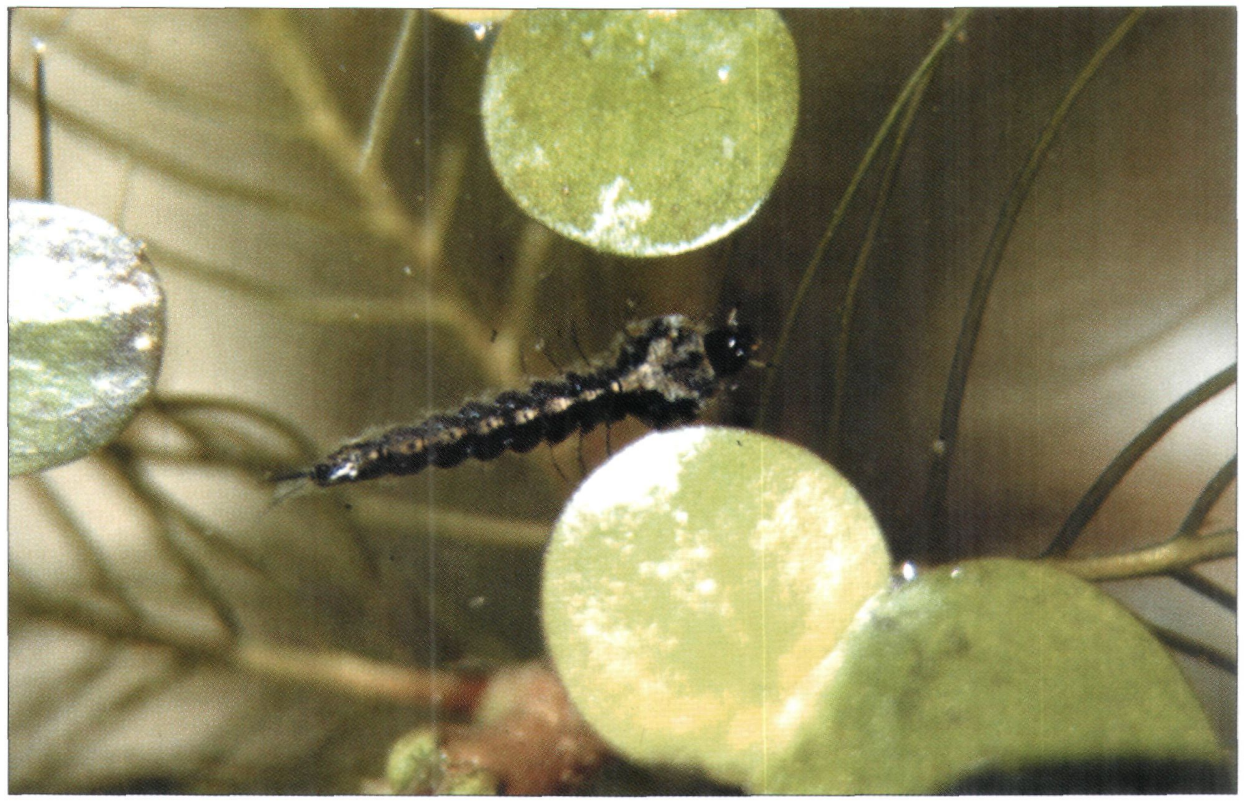

2. ábra: A foltos maláriaszúnyog (Anopheles maculipennis) lárvája Fotó: Tóth S.

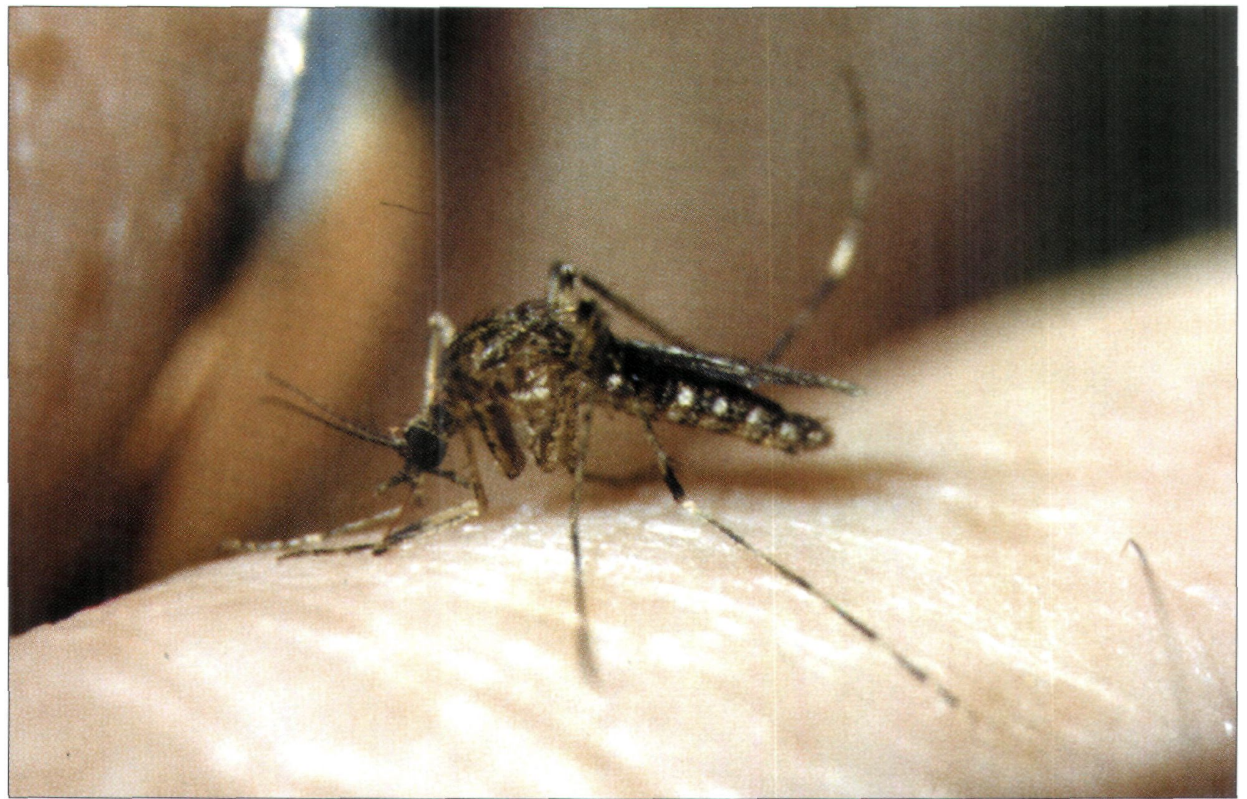

3. ábra: A mocsári szúnyog (Mansonia richiardii) nôsténye vérszívás közben Fotó: Tóth $\mathrm{S}$. 
nak csak néhány pontjáról ismerjük.

Culex martinii Medschid, 1930 - T'óth (elökészületben). Ritka, Magyarországnak csak néhány pontjáról ismerjük.

Culex modestus Ficalbi, 1890 - Mihályi 1941, Mihályi et al. 1952a, 1953, Tóth 1981, 1992, 1995, 1996

Culex pipiens Linnaeus, 1758 - Kertész 1904, Mihályi 1941, Mihályi et al. 1952a, 1953, Tóth 1981, 1992, 1995, 1996

Culex pipiens molestus Forskal, 1775 - Tóth (elôkészületben). Bár Magyarország kevés pontjáról ismert, de ritkának nem nevezhető alfaj. Magyar nevén „házi szúnyog”, a szabadban ritkán találkozhatunk vele, a lakásban viszont olykor egész télen át csípi az embert.

Culex territans Walker, 1856 - Mihályi 1941, Mihályi et al. 1952a, 1953, Tóth 1981, 1996

Culex theileri Theobald, 1903 - Mihályi et al. 1952a, 1953, Tóth (elökészületben). Ritka.
Culiseta alaskaensis (Ludlow, 1906) - Mihályi et al. 1952a, 1953, Tóth (elökészületben)

Culiseta annulata (Schrank, 1776) - Mihályi 1941, Mihályi et al. 1952a, 1953, Tóth 1981, 1992, 1995, 1996

Culiseta morsitans (Theobald, 1901) - Mihályi 1941, Mihályi et al. I952a, 1953, Tóth 1981, 1992, 1995

Culiseta subochrea (Edwards, 1921) - Mihályi - Gulyás 1963, Tóth (elökészületben) Ritka.

Mansonia richiardii (Ficalbi, 1889) -Kertész 1904, Mihályi 1941, Mihályi et al. 1952a, 1953, Szilády 1941, Tóth 1981, 1991, 1996

Uranotaenia unguiculata Edwards, 1913. Tóth 1996. Viszonylag ritka faj, de a Dráva mente és a Balaton déli partjának elég sok pontjáról elókerült.

\section{Irodalom}

KERTÉSz K. 1904: A magyarországi szúnyogfélék rendszertani ismertetése - Állattani Közl., 3: 1-75.

LóRINCZ F., MinÁLYI F. 1937a: Adatok a hazai maláriakérdés ismeretéhez. III. Tanulmány az Anopheles maculipennis varietasok hazai elófordulására vonatkozólag - Népegészségügy, 15-20: 30-42.

LỚRINCZ F. , MIHÁLYI F. 1937b: Adatok a hazai malária-kérdés ismeretéhez. IV. Az Anopheles maculipennis varietasok szerepe a malária terjesztésében hazánkban. - Népegészségügy, 18: 1-9.

LörINCZ F., MıHÁLYI F. 1938: Adatok a hazai malária-kérdés vizsgálatához (Anopheles maculipennis tanulmányok) - Állattani Közl., 35: 1-11.

MıHÁLYI F. 1941: A Balaton-partvidék Culicidái - Magyar Biol. Kut. Munk., 13: 168-174.

MiHÁLYI F., Gulyás M. 1963: Magyarország csípő szúnyogjai - Akad. Kiadó, Bp., pp. 1-229.

MiHÁlyI F., SOÓs Á. - SZTANKAY M. 1952a: Ökologie und Ethologie der Culiciden im Ufergebiet des Balaton Sees. - Ann. Biol. Univ. Hung., 1: 79-105.

Mihályi F., Soós, Á., SzTANKaY-Gulyás, M., Zoltai, N. 1952b: Préparatifs entomologiques pour la lutte contre les Moustiques piqueurs et le paludisme sur les bords du lac Balaton, I. partie. Acta Biol. Hung., 3: 333-364.

Mihályi F., Soós Á., SzTANKAy Sz., ZoltaI N. 1953: A Balaton-menti községek szúnyoghelyzete és a gyakorlati védekezés módjai - A Magy. Tud. Akad. Biol. Oszt. Közlem., 2: 35-94.

Soós Á., MıHÁlyı F. 1952: A csípószúnyogok és a malária elleni küzdelem rovartani elókészítése a Balaton partján - A Magy. Tud. Akad. Biol. Oszt. Közlem., 3: 555-587.

SzILÁDY Z. 1941: Diptera kutatás a Balaton környékén - Magyar Biol. Kut. Munk., 13: 259-267.

THALHAMmer J. 1899: Ordo Diptera. In: A Magyar Birodalom Állatvilága. Fauna Regni Hung., 3: 5-76.

TóтH S. 1981: Adatok a barcsi borókás csípőszúnyog faunájához (Diptera: Culicidae) - Dunántúli Dolg. Term.tud. Sor., 2: 133-142.

Tórh S. 1991: Adatok a mocsári szúnyog, Mansonia (Coquillettidia) richiardii (Ficalbi, 1889) életmódjához és magyarországi elterjedéséhez (Diptera: Culicidae) - Fol. Mus. Hist.-nat. Bakonyiensis, 10: 137-178.

TóTH S. 1992: Vegyes kétszárnyú (Diptera) adatok a Boronka-melléki Tájvédelmi Körzet faunájához - Dunántúli Dolg. Term.tud. Sor., 7: 273-287. 
Tóth S. 1995: Adatok a Dráva mente kétszárnyú (Diptera) faunájához - Dunántúli Dolg. Term. tud. Sorozat 8: 161-172.

TótH S. 1996: Csípôszúnyog biomonitorozás a Kis-Balaton Vízminöségjavító Rendszer II. Ütemének területén (Diptera: Culicidae) - 2. Kis-Balaton Ankét, 1996 (Összefoglaló értékelés a KBVR 1991-1995 közötti kutatási eredményeiról), p. 346-357.

TótH S. A Balaton-medence csípőszúnyog-faunája (Diptera: Culicidae) - elókészületben

\title{
Checklist of culicid flies of Somogy county
}

(Diptera: Culicidae)

\section{SÁNDOR TÓTH}

The mosquito fauna of Hungary is well explored. The first data referring to the culicid fauna in Somogy county (Csurgó) can be found in the chapter written on Diptera in the Fauna Regni Hungariae (The Fauna of the Hungarian Empire, Thalhammer 1899): [Aedes annulipes (Meigen, 1830), Aedes cantans (Meigen, 1818). A couple of years later, a taxonomic survey written on the mosquitos of Hungary (KERTÉSZ 1904) reported the occurrence of three more species Aedes dorsalis (Meigen, 1830), Culex pipiens Linnaeus, 1758, Mansonia richiardii (Ficialbi, 1889)] from the southern side of Lake Balaton (Balatonőszöd).

From the late 1930s until the early 1950s, mosquitos were studied mainly on the southern side of Lake Balaton, and later - with less intensity though alongside the River Dráva, and in the Boronka-melléki Landscape Protection Area.

According to the data available at the present, the occurrence of exactly $80 \%$ of the Hungarian fauna is proved to be found in Somogy county. The fauna is rich in rare and special elements such as: Aedes communis (De Geer, 1776), Aedes leucomelas (Meigen, 1804), Aedes pulchritarsis (Rondani, 1872), Anopheles algeriensis Theobald, 1903, Anopheles hyrcanus (Pallas, 1771), Culex theileri Theobald, 1903, Culiseta alaskaensis (Ludlow, 1906), Culiseta subochrea (Edwards, 1921).

\author{
Author's address: \\ Dr. Sándor TóTH \\ H-8420 Zirc \\ Széchenyi u. 2. \\ HUNGARY
}

